\title{
Questes
}

\section{La mort au Moyen Âge : éléments bibliographiques}

\section{(2) OpenEdition}

1 Journals

Édition électronique

URL : http://journals.openedition.org/questes/1802

DOI : 10.4000/questes. 1802

ISSN : 2109-9472

Éditeur

Les Amis de Questes

Édition imprimée

Date de publication : 15 mai 2003

Pagination : 14-16

ISSN : 2102-7188

\section{Référence électronique}

"La mort au Moyen Âge : éléments bibliographiques », Questes [En ligne], 5 | 2003, mis en ligne le 01 janvier 2014, consulté le 15 septembre 2020. URL : http://journals.openedition.org/questes/1802 


\section{La mort au Moyen Age : éléments de bibliographie}

- À Réveiller les morts. La mort au quotidien dans l'Occident médiéval, sous la direction de D. ALEXANDRE-BIDON, C. TREFFORT, Lyon, Presses universitaires, 1993.

- ALEXANDRE-BIDON (D.), La mort au Moyen Âge (XIIIe-XVIe siècle), Paris, Hachette, 1998 (La vie quotidienne).

- ARIES (P.), Essais sur l'histoire de la mort en Occident du Moyen Age à nos jours, Paris, Le Seuil, 1975.

- ARIES (P.), Images de l'homme devant la mort, Paris, Le Seuil, 1983.

- ARIES (P.), L'homme devant la mort, Paris, Le Seuil, 1977.

- BASCHET (J.), Les justices de l'au-delà. Les représentations de l'enfer en France et en Italie (XIIe-XVe siècle), Roma, Ecole française de Rome, 1993, 700 p.

- BAYARD (F.), L'art du bien mourir au XVe siècle. Etude sur les arts du bien mourir au bas Moyen Age à la lumière d'un Ars moriendi allemand du XVe siècle, Paris, Presses de l’Université de Paris-Sorbonne, 1999, 245 p.

- BINSKI (P.), Medieval Death. Ritual and Representation, Londres, British Museum Press, 1996.

- BONANDRINI (G.), Il trionfo della morte e la danza macabra, Clusone 1485, Bergamo, Ed. Cesare Ferrari, 1985.

- BOZOKY (E.) «Les démons et les morts. Croyances et pratiques pour protéger les morts contre les démons au Moyen Âge », in Enfer et paradis. L'au-delà dans l'art et la littérature en Europe, Conques, 1995 (Cahiers de Conques, 1), pp. 311331.

- CERVINI (F.), «I morti difensori dei vivi. Note di iconologia e religiosità popolare sul culto dei morti a Taggia e Riva », in Bollettino della comunità di Villaregia, 1, 1, 1990, pp. 42-55. 
- CHIFFOLEAU (J.), «Pratiques funéraires et images de la mort à Marseille, en Avignon et dans le Comtat Venaissin (vers 1280-vers 1350) », in La religion populaire en Languedoc du XIIIe à la moitié du XIVe siècle, Cahiers de Fanjeaux, $\mathrm{n}^{\circ}$ 11, Toulouse, Privat, 1976, pp. 271-304.

- CHIFFOLEAU (J.), « Sur l'usage obsessionnel de la messe pour les morts à la fin du Moyen Age ", in Faire croire. Modalités de la diffusion et de la réception des messages religieux du XIIe au XVe siècle, Table ronde organisée par l'Ecole française de Rome, Roma, 22-23 juin 1979, sous la direction de A. VAUCHEZ, Roma, Ecole française de Rome, 1981, pp. 235-256.

- CHIfFOlEAU (J.), La comptabilité de l'au-delà : les hommes, la mort et la religion dans la région d'Avignon à la fin du Moyen Age (vers 1320-1480), Roma, Ecole française de Rome, 1980, 494 p.

- CONTENSON (M.-L. de), « Le dit des trois morts et des trois vifs à Ennezat (Puy-de-Dôme) France ", in Actes du 5e Congrès des Danses macabres d'Europe, Straubing, 1992, pp. 187-195.

- COURCELLES-LAVREDINE (D. de), L'écriture dans la pensée de la mort : les «goigs» de Catalogne, Paris, École nationale des chartes, 1993 (Mémoires et documents).

- COURCELlES-LAVREDINE (D. de), Les histoires de saints, la prière et la mort en Catalogne, Paris, Publications de la Sorbonne, 1990 (Mémoires et documents du CRES).

- CROUZET-PAVAN (E.), «Imaginaire et politique. Venise et la mort à la fin du Moyen Age », in Mélanges de l'Ecole française de Rome, 93, 1981, pp. 467-493.

- DEMOUY (P.), « Recherche d'une comptabilité de l'au-delà : le catalogue des morts de Saint-Remi de Reims (945-1232) », in Compter les Champenois, sous la direction de P. DEMOUY, C. VULLIEZ, Reims, Presses universitaires de Reims, 1998, pp. 95-105. 
- Der Heidelberger Totentanz von 1485, sous la direction de Manfred LEMMER, Frankfurt am Main, Insel Verlag, 1991.

- DeREgnaUCOURT (J.-P.), Autour de la mort à Douai. Attitudes, pratiques et croyances, 1250-1500, Lille, Université de Charles-de-Gaulle, 1993 (thèse).

- DI NOLA (A. M.), La Nera Signora. Antropologia della morte, Roma, Newton \& Compton, 1995, 416 p.

- DUBUIS (P.), Les vifs, les morts et le temps qui court. Familles valaisannes 1400-1550, Lausanne, Faculté des Lettres-Université de Lausanne, Cahiers lausannois d'histoire médiévale 16, 1995, 318 p.

- FOL (M.), « A la table des morts. Repas funéraires, solidarités épulaires et économie du Salut en Savoie au temps de la religion flamboyante (vers 1330-vers 1561) », in Chemins d'histoire alpine. Mélanges dédiés à la mémoire de Roger Devos, sous la direction de M. FOL, C. SORREL, H. VIALLET, Annecy, Les amis de Roger Devos, 1997, pp. 59-128.

- FOL (M.), « Les chanoines, les comptes et la mort. Regards sur la comptabilité de la collégiale de Sallanches à la fin du Moyen Âge (vers 1419-vers 1521) », in Recherches sur l'économie ecclésiale à la fin du Moyen Âge. Autour des collégiales de Savoie, Mémoires et documents publiés par l'Académie salésienne, 97 (1991), pp. 69-92.

- FUMAGALLI (V.), « Il paesaggio dei morti. Luoghi d'incontro fra i morti e i vivi sulla terra nel Medioevo », in Quaderni storici, n 50, Bologne, Il Mulino, 1982, pp. 411-425.

- HENRIET (P.), « Mort sainte et mort des blasphémateurs à Fleury (XIe-XIIe s.) », in La mort en Europe médiévale et moderne, Wroclaw, 1997 (Historia, 129 ; Acta Universitatis Wratislaviensis, 1863), pp. 135-148.

- IOGNA-PRAT (D.), « Des morts très spéciaux aux morts ordinaires : la pastorale funéraire clunisienne (XIe-XIIe s.) "), in La mort des grands, Médiévales, 31 
(1996), pp. 79-91.

- KAISER (G.), Der tanzende Tod, Frankfurt am Main, Insel Verlag, 1982, 351 p.

- KIENING (Ch.), « Le double décomposé. Rencontres des vivants et des morts à la fin du Moyen Age », in Annales H.S.S., 50, n. 5, 1995, pp. 1157-1190.

- KLAPISCH-ZUBER (C.), « Les femmes et la mort à la fin du Moyen Âge », in Ilaria del Carretto e il suo monumento. La donna nell' arte, la cultura e la società del '400, sous la direction de S. TOUSSAINT, Lucques, Istituto storico lucchese, 1995, pp. 207-221.

- KLAPISCH-ZUBER (C.), «L'enfant, la mémoire et la mort dans l'Italie des XIVe et XVe siècles », in Histoire de l'enfance en Occident de l'Antiquité au XVIIe siècle, t. 1, sous la direction de E. BECCHI et D. JULIA, Paris, Seuil, 1998, pp. 200-230.

- La mort au Moyen Age, Actes du colloque de la Société des médiévistes de l'enseignement supérieur public, Strasbourg, Istra, 1971.

- La mort et l'au-delà en France méridionale (XIIe-XVe siècle), Toulouse, Privat, 1998 (Cahiers de Fanjeaux, 33).

- L'archéologie funéraire, Paris, Errance, 2000.

- LAUWERS (M.), «Le cimetière dans le Moyen Age latin. Lieu sacré, saint et religieux », in Annales, H.S.S., $54^{\mathrm{e}}$ année, n. 5, septembre-octobre 1999, pp. 10471072 .

- LAUWERS (M.), La mémoire des ancêtres, le souci des morts. Morts, rites et société au Moyen Âge (diocèse de Liège, XIe-XIIIe siècle), Paris, Beauchesne, 1997 (Théologie historique, 103).

- Le cadavre. Anthropologie, archéologie, imaginaire social, Actes du Colloque de Lyon, 1996, sous la direction de J. CHIFFOLEAU et A. PARAVICINIBAGLIANI, Lausanne, 1998.

- LE GOFF (J.), La naissance du Purgatoire, Paris, Gallimard, 1981. 
- Le sentiment de la mort au Moyen Age, études présentées au Ve colloque de l'Institut d'études médiévales de l'Université de Montréal, sous la direction de C. SUTTO, Univers, 1979.

- Les moines et la mort, Histoire médiévale et archéologie 6 (1993) ; trad. angl., Cistercian Studies Quaterly, 34/2 (1999).

- LETT (D.), « De l'errance au deuil. Les enfants morts sans baptême et la naissance du limbus puerorum aux XIIe-XIIIe siècles », in La petite enfance dans l'Europe médiévale et moderne, sous la direction de R. FOSSIER, Toulouse, Presses universitaires de Toulouse-le-Mirail, 1997 (Flaran, 16), pp. 77-92.

- LETT (D.), « Dire la mort de l'enfant qui va ressusciter dans quelques récits de miracles des XIIe-XIIIe siècles ", in L'enfant et la mort, sous la direction de P. ELLINGER, Reims, Presses universitaires de Reims, 1997, pp. 137-155.

- LETT (D.), « Faire le deuil d'un enfant mort sans baptême au Moyen Âge : la naissance du limbe pour enfants aux XIIe-XIIIe s. ", in Devenir, 7/1 (1995), pp. 101-112.

- L'HERMITE-LECLERCQ (P.), « La femme, la recluse et la mort », in Muerte, Religiosidad y cultura popular, siglos XIII-XVIII, sous la direction de E. SERRANO MARTIN, Saragosse, 1994, pp. 151-162.

- Life and Death in Fifteenth-Century Florence, sous la direction de M. TETEL, R. G. WITT, et R. GOFFEN, Londres, Duke University Press, 1989.

- LORCIN (M.-T.), Vivre et mourir en Lyonnais à la fin du Moyen Age, Paris, CNRS, 1981.

- MARANDET (M.-C.), Le souci de l'Au-delà : la pratique testamentaire dans la région toulousaine (1300-1450), Perpignan, Presses universitaires de Perpignan, 1998.

- MClAughlin (M.), Consorting with Saints. Prayer for the Dead in Early Medieval France, Ithaca et Londres, 1994. 
- Moines et moniales face à la mort, Actes du colloque de Lille, 2-3-4 octobre 1992, CAHMER/Paris XIII-CREDHIR Université catholique de Lille, vol. VI, Lille, 1993.

- MOLLAT (M.), « Le sentiment de la mort et de la vie et la pratique religieuse à la fin du Moyen Age », in Etudes sur l'économie et la société de l'Occident médiéval (XIIe-XVe siècles), Londres, Variorum Reprints, 1977, pp. 201-229.

- PASCHE (V.), "Pour le salut de mon âme ». Les Lausannois face à la mort (XIVe siècle), Lausanne, Cahiers lausannois d'histoire médiévale, 2, 1990.

- POLO DE BEAULIEU (M. A.), « Le Lundi des trépassés. Création, diffusion et réception d'un rituel », in Annales, H.S.S., 53 ${ }^{\mathrm{e}}$ année, n. 6, novembre-décembre 1998, pp. 1191-1217.

- RICCI (G.), Il principe e la morte. Corpo, cuore, effigie nel Rinascimento, Bologne, Il Mulino, 1998, 202 p.

- RIVERA (A.), Il mago, il santo, la morte, la festa : forme religiose nella cultura popolare, Bari, Dedalo, 1988, 415 p.

- ROUCHE (M.), « Radegonde, une mort programmée », in Moines et moniales face à la mort, Histoire médiévale et archéologie, 6 (1993), pp. 13-17.

- SCHMITT (J.-C.), «Les masques, le diable et la mort dans l'Occident médiéval », in Razo. Cahiers du Centre d'études médiévales de Nice, t. 6, 1986, pp. 87-119.

- SCHMITT (J.-C.), Les revenants. Les vivants et les morts dans la société médiévale , Paris, Gallimard, 1994 (Bibliothèque des histoires).

- TENENTI (A.), «La rappresentazione della morte di massa nel Decameron », in Tod in Mittelalter, sous la direction de A. BORST, G.V. GRAEVENITZ et alii, Konstanz, Universitätsverlag Konstanz, 1993, pp. 209-220.

- TENENTI (A.), Il senso della morte e l'amore della vita nel Rinascimento, Torino, Einaudi, 1989, 511 p. 
- TILLIETTE (J.-Y.), « La triple mort de Roland. L'épisode de Roncevaux dans l'épopée latine du Moyen Âge », in Mélanges de philologie et de littérature offerts à Michel Burger, Genève, Droz, 1994, p. 273-288.

- Tod in Mittelalter, sous la direction de A. BORST, G.V. GRAEVENITZ et alii, Konstanz, Universitätsverlag Konstanz, 1993.

- TREFFORT (C.), L'Église carolingienne et la mort. Christianisme, rites funéraires et pratiques commémoratives, Lyon, CIHAM-Presses universitaires de Lyon, 1996 (Histoire et archéologie médiévales, 3).

- Visages de la mort dans l'histoire du Midi toulousain, sous la direction de J.-L. LAFFONT, Universatim Pyrégraph, 1999.

- VOVELlE (G.), VOVELlE (M.), «Vision de la mort et de l'au-delà en Provence d'après les autels des âmes du Purgatoire XVe-Xxe siècle », in Cahiers des Annales, n 29, 1970.

- VOVELlE (M.), L'Heure du grand passage. Chroniques de la mort, Paris, Gallimard, Découvertes, 1993.

- VOVELlE (M.), La Mort et l'Occident de 1300 à nos jours, Paris, Gallimard, 1983.

- WIRTH (J.), La jeune fille et la mort, Genève, Librairie Droz, 1979, 194 p.

- ZARRI (G.), «Purgatorio particolare e ritorno dei morti tra Riforma e Controriforma : l'area italiana », in Quaderni storici, ${ }^{\circ}$ 50, 1982, pp. 466-497. 